\title{
La estrategia actual de Ecuador frente al Régimen Internacional de Inversiones
}

\author{
Edwin Santiago Núñez Naranjo snunez@uotavalo.edu.ec \\ Universidad Andina Simón Bolívar
}

Recibido:06/02/2020.

Aceptado:17/10/2020.

\begin{abstract}
Resumen: El objetivo de este trabajo fue descubrir la estrategia actual del Ecuador sobre la atracción de inversión extranjera directa. Se realizó un acercamiento histórico al Régimen Internacional de Inversiones en el que Ecuador se ha desenvuelto y se elaboró una indagación cualitativa, bibliográfica y de campo respecto de la política exterior ecuatoriana en materia de inversiones a partir de las acciones ejecutadas entre 2007 y 2019 por sus gobiernos. El análisis ha demostrado que los flujos de inversión extranjera directa recibida por Ecuador no han mejorado, a causa de un discurso cambiante: entre 2007 y 2017, al denunciar el sistema de arbitraje y los acuerdos internacionales de inversión firmados y entre 2017 y 2019 , al promover la firma de nuevos convenios.
\end{abstract}

Palabras clave: Ecuador; estrategia; Inversión extranjera directa; Tratados bilaterales de inversión; Países en desarrollo.

* Cómo citar este artículo: Núñez Narajo, E. (2020). La estrategia actual de Ecuador frente al Régimen Internacional de Inversiones. Relaciones Internacionales, 29(59), 108. https://doi.org/10.24215/23142766e108

Editor: Juan Alberto Rial, Instituto de Relaciones Internacionales Facultad de Ciencias Jurídicas y Sociales (Universidad Nacional de La Plata)
Entidad editora: Relaciones

Internacionales, es una publicación del Instituto de Relaciones Internacionales (Facultad de Ciencias Jurídicas y Sociales (Universidad Nacional de La Plata Argentina) Vol 29 - no 59/2020

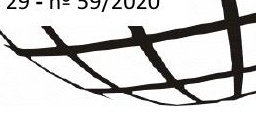




\title{
The Ecuadorian Strategy regarding the International Invest- ment Regime
}

\section{Edwin Santiago Núñez Naranjo1}

\begin{abstract}
The objective of this work was to discover Ecuador's current strategy to attract foreign direct investment. A historical review of the International Investment Regime in which Ecuador has participated as well as a qualitative, bibliographic and field examination of Ecuadorian foreign policy regarding investments between 2007 and 2019 were carried out. The analysis has shown that the Ecuadorian flows of foreign direct investment have not increased due to a changing discourse: between 2007 and 2017, denouncing the dispute resolution system established and the international investment agreements signed; between 2017 and 2019, promoting the signing of new agreements.
\end{abstract}

Keywords: Ecuador; strategy; Foreign Direct Investment; Bilateral Investment Treaties; Developing countries.

1 Magister en Relaciones Internacionales, Universidad Andina Simón Bolívar, Doctorando del Programa de Desarrollo Regional e Integración Económica de la Universidad de Santiago de Compostela, Docente Tiempo Completo de la Universidad de Otavalo. Experto en negocios internacionales y Fundador de la empresa Strategyline, Quito- Ecuador. 


\section{Introducción}

La inversión, en términos generales, no solamente ha estado provista de diversas definiciones sino también interpretaciones a lo largo de la historia. Etimológicamente, el término proviene del latín invertere, que viene del verbo verter y que implica pasar un objeto de un lugar a otro. En su interpretación más clásica y empírica, al término se lo entendía como el sacrificio de un recurso por obtener más en el futuro, pensamiento que dio paso a una visión general de la inversión en materia económica, conceptualizada ya como "cualquier instrumento en el que se depositan fondos con la expectativa de que genere ingresos positivos y/o conserve o incremente su valor" (Gitman y Joehnk, 2009, pág. 3). Así es como en materia económica se entendía a la inversión como un activo o un derecho de propiedad que le permitía al tenedor mantener o incrementar su capital. En el campo jurídico, sin embargo, se circunscribió el término a "todo bien sobre el cual un inversionista ejerce propiedad o control directa o indirectamente" (Lander, 1998, pág. 4).

Estas conceptualizaciones evolucionaron hasta el ámbito de la economía política, en el cual se entendió después de la Segunda Guerra Mundial como un instrumento político para proveer el desarrollo económico, cuyas fuentes pueden ser internas o externas. Esta última acepción permite considerar a la inversión como un instrumento de política exterior sobre la cual los países se han preocupado por reglamentar. En el caso ecuatoriano, se entiende a la inversión como "la inversión productiva, independientemente de los tipos de propiedad, al flujo de recursos destinados a producir bienes y servicios, a ampliar la capacidad productiva y a generar fuentes de trabajo en la economía nacional" (COPCl, 2018, pág.9).

La inversión es, entonces, un aporte de recursos con fines productivos o de reproducción de capital, donde el valor aportado produce un retorno positivo al inversor, el cual puede presentarse de forma indirecta o directa. El tema les ha generado gran interés a los Estados ya que, por una parte, se la puede utilizar como una fuente de financiamiento externa (inversión indirecta) y, por otra, como un mecanismo de atracción de capitales, maquinaria y mano de obra especializada en sectores de la economía a los que el propio país no tiene la capacidad de hacer frente (inversión directa) (Montoya, 2006, págs. 22-23).

La inversión extranjera directa (conocida por sus siglas IED) incluye la participación activa del inversionista en la actividad en la cual inyecta los recursos, generalmente a través de la participación en el proceso productivo; es aquella en la que el inversionista adquiere directamente un derecho sobre un valor o propiedad. Por ese motivo, es característica de este tipo de inversión su amplia duración en el tiempo, por lo que se la destina principalmente a proyectos a largo plazo. "La inversión extranjera directa es una categoría de la inversión transfronteriza relacionada con el hecho de que un inversionista residente en una economía ejerce el control o un grado significativo de influencia sobre la gestión de una empresa que es residente en otra economía" (Fondo Monetario Internacional, 2009, pág. 106). Dicha conceptualización parte de una visión institucionalista internacional donde es vista a "la inversión directa como una categoría de inversión que realiza un residente de una economía (el inversor directo) con el objetivo de establecer un interés duradero en una empresa (la empresa de inversión directa) residente en una economía diferente de la del inversor directo" (Organización para la Cooperación y el Desarrollo Económico, 2008, pág. 17). 
Los países desarrollados necesitan de nuevos mercados para llevar su exceso de producción y, a su vez, los países de economías en desarrollo necesitan cubrir sus necesidades tecnológicas y de financiación, lo que conlleva a la interdependencia de las economías mundiales. De esto resulta el comercio internacional y, por tanto, la inversión extranjera (Montoya, 2006, págs. 25-27). La IED se transfiere, por lo general, desde multinacionales que inician la construcción de nuevas plantas o la ampliación de sus instalaciones existentes en países extranjeros. Los países pueden ser ricos en recursos naturales, como petróleo y minerales, pero no tienen la tecnología adecuada para extraerlos; por lo que recurren a empresas multinacionales que poseen tecnologías desarrolladas y experiencia, y que están interesadas en invertir en nuevos mercados crecientes. El crecimiento vertiginoso de la población en el mundo incrementa las necesidades sociales básicas, como educación, salud, vivienda, alimentación, trabajo, etc., demandas sociales que los gobiernos deben atender con prioridad, pero al contar con recursos limitados a nivel interno buscan en la inversión extranjera el mecanismo propicio para la reducción de la pobreza (Kato-Vida, 2013, págs. 209-210).

Se concibe entonces a la Inversión Extranjera Directa (IED) como una fuente de aumento de la productividad, conocimientos especializados, tecnología, exportaciones, empleo, que contribuye al desarrollo económico y social a largo plazo. La inversión extranjera indirecta (conocida por sus siglas IEI), también llamada de cartera, busca la obtención de utilidades a corto plazo; un claro ejemplo de este tipo de inversión es el otorgamiento de créditos en el país por una persona no residente o bien la adquisición de un paquete minoritario de acciones de una sociedad para su pronta liquidación. La IEI es utilizada por los gobiernos para financiar sobre todo el gasto corriente, e implica altos intereses y un escaso compromiso de parte del inversionista, quien busca rendimiento y no generación productiva, a diferencia de la IED, que se ha probado implica la promoción de la inversión local al mismo tiempo que reduce la corrupción (Kato-Vida, 2013, págs. 210-211).

Habiendo aclarado la terminología relacionada con la inversión productiva y no productiva extranjera, que ha delineado el contexto conceptual en el que Ecuador se ha desenvuelto desde el año 2007, los siguientes párrafos se centrarán en ofrecer argumentos que permitan responder las siguientes preguntas respecto a la estrategia de Ecuador frente al régimen de inversiones internacional: ¿las acciones emprendidas por el gobierno ecuatoriano en este periodo de análisis han sido parte de una política exterior planificada, coherente y vinculada con las demás políticas emprendidas por el gobierno en otros temas? y ¿las políticas y actividades adoptadas por el gobierno en materia de protección y promoción de la inversión en el periodo en mención han servido para mejorar los flujos de inversión extranjera directa proveniente del exterior así como la calidad de la inversión extranjera?. Para ello, se realiza un análisis histórico de la regulación de la IED en el régimen internacional de inversiones, una revisión situacional de la IED en Ecuador y un análisis de la política exterior ecuatoriana respecto de las formas de regulación, los mecanismos para su atracción, para la solución de controversias entre las partes y su postura internacional. 


\section{Regulación de la inversión extranjera en el régimen internacional de in- versiones}

La fuerza fue el recurso que se utilizó entre 1820 y 1914 para proteger a los inversionistas. En lo posterior, se utilizó la doctrina de nacionalización de la relación jurídica de los extranjeros, lo que significaba que los Estados debían brindar un trato nacional a las compañías extranjeras. Ya en la década de 1960 se decretaron principios que conformaron la base de los tratados bilaterales de protección de inversiones (Prieto, 2012, págs. 17-19) y con ello se delineó el modelo bilateral de negociación de la inversión desplazando al multilateralismo, el cual tuvo intentos fallidos, como el Acuerdo Multilateral de Inversiones (AMI). Con el bilateralismo, se institucionalizó el uso del arbitraje en la solución de controversias en materia de inversión, el cual se ha constituido en un mecanismo válido y aceptado a nivel mundial para regular controversias sobre inversión, que en 2018 presentó disconformidad principalmente para las empresas transnacionales que buscaban una resolución rápida de sus conflictos en la materia y que el mecanismo no ha podido satisfacer. Sin embargo, hasta finales de 2019 el arbitraje se ha mantenido como el mecanismo más idóneo para la resolución de controversias que surjan entre Estados y empresas por cuestiones relativas a inversiones.

Varias instituciones a nivel mundial se han consolidado como las defensoras del libre derecho de los Estados y empresas por debatir sobre el régimen actual y se han convertido en los organismos propulsores de estudios sobre una inversión extranjera que promueva un mayor flujo, entre ellos: la Cámara de Comercio Internacional (CCI), el Banco Mundial (BM), la Comisión Económica para América Latina (CEPAL), la Conferencia de las Naciones Unidas sobre Comercio y Desarrollo (UNCTAD) y la Organización para la Cooperación y el Desarrollo Económico (OECD).

La Secretaría de la Conferencia de las Naciones Unidas sobre Comercio y Desarrollo (UNCTAD) se ha convertido en la entidad internacional no gubernamental encargada de actuar como centro de coordinación de las Naciones Unidas para el tratamiento integrado del comercio y desarrollo así como de cuestiones anexas. Es la institución líder de la promoción y aplicación de un programa de acuerdos internacionales de inversión (All), que tiene como objetivo "ayudar a los países en desarrollo a participar lo más eficazmente posible en la elaboración de normas relativas a la inversión internacional” (UNCTAD, 2008a, pág. 6).

Dicho programa constituye el mayor esfuerzo actual por alcanzar un consenso intergubernamental en materia de inversiones, a través de actividades basadas en tres pilares: 1) en la investigación y análisis de políticas sobre inversiones (que incluyen la creación de una colección avanzada de estudios y publicaciones temáticas), 2) en la asistencia técnica para el fomento de la capacidad institucional (que involucra la realización de cursos de formación para fortalecer la capacidad de los participantes en el manejo de temas relacionados al régimen de All), y 3 ) en la construcción de un consenso intergubernamental por medio de la creación de instancias inclusivas para promover el diálogo y la retroalimentación en temas actuales sobre regulación de inversiones (tales como, seminarios nacionales, simposios regionales y foros internacionales) (UNCTAD, 2013). 
Respecto al punto 3, se ha creado una estructura de Conferencias para motivar el consenso intergubernamental en diversos temas, incluida la sección de Acuerdos Internacionales de Inversión. La Conferencia General de la UNCTAD se lleva a cabo cada cuatro años y se la desarrolla en conjunto con el Foro Mundial de Inversiones, el cual se desarrolla de forma bienal y se ha instaurado desde el año 2008, habiéndose realizado cuatro hasta 2019 (AccraGhana 2008, Xiamen- China 2010, Doha- Catar 2012, Ginebra-Suiza 2014, Nairobi-Kenia 2016, Ginebra-Suiza 2018). Además, se desarrollan Conferencias anuales sobre All, las cuales reúnen a representantes gubernamentales, expertos en el tema, delegados de empresas multinacionales, la sociedad civil y diversos beneficiarios de All con el fin de intercambiar experiencias y las mejores prácticas, discutir opciones para un desarrollo amistoso sustentable de las cláusulas en los All y trazar el camino que permita mejorar la gobernanza global en inversiones.

La Declaración de Accra reconoció el rol de los países en desarrollo (PED) y los beneficios de la IED en ellos. Además, los comprometió a defender el comercio multilateral que promueva el desarrollo, así como redoblar los esfuerzos para concluir con las 32 negociaciones de la ronda de Doha, respetar lo alcanzado en la Conferencia Ministerial de Hong Kong sobre el libre acceso a mercados y proporcionar contingentes a los PED (UNCTAD, 2008b, págs. 2-7).

Por su parte, en Xiamen - China 2010 se destaca la predisposición de los altos representantes empresariales por emplear los flujos de IED para recuperarse de la crisis financiera de 2008 y la ocasión de explorar los beneficios de la cooperación sur-sur, al observar que los flujos de inversión que provienen de países emergentes se han incrementado (UNCTAD 2008b, pág. 11). Se asumió la necesidad de adoptar un enfoque de políticas de inversión holístico, incentivar la responsabilidad corporativa, controlar el ritmo del cambio que permita proteger a los Estados receptores de IED mientras se ofrecen beneficios a los inversionistas, construir uniones locales entre empresas y Estados, y mejorar los niveles de investigación y la información derivada (UNCTAD, 2008b, pág. 13).

En Doha - Catar 2012, frente a la aparición de nuevos inversores, al surgimiento de los países del sur como destinos atractivos para la inversión y a la cambiante situación de la inversión internacional, se concluyó que es necesario implementar políticas más eficaces que faciliten la inversión extranjera; que a nivel nacional permitan estimular la diversificación económica y la transformación estructural de las economías, mientras que a nivel internacional pongan orden al crecimiento abrupto de acuerdos internacionales de inversión para garantizar su coherencia, lo que implicaba un enfoque mundial más coordinado para enfrentar los retos modernos. En consecuencia, se planteó fomentar las alianzas (principalmente público-privadas) para liberar a los países de las circunstancias económicas difíciles y atraer más inversión (UNCTAD, 2012, págs.1-5).

En 2014, en el Foro Mundial de Inversiones, realizado en Ginebra-Suiza, se reforzó la dicotomía entre quienes apoyan la firma de sólidos Tratados Bilaterales de Inversión (TBI) para liberalizar y proteger los flujos de IED, en apoyo al cuidado de los intereses de los inversionistas, el acceso al mercado y el sistema de solución de controversias, y quienes respaldan la imperante necesidad de un cambio profundo en el régimen y en la reforma del sistema de Solución de Controversias entre Inversores y el Estado (SCIE), particularmente 
en lo relacionado a introducir nuevos elementos de empoderamiento en los tratados de inversión, tanto en liberalización como en transparencia. Se ha definido el desarrollo de una hoja de ruta para la reforma del régimen de los All, propuesta que se reforzó en la reunión de expertos promovida por la UNCTAD para 2015 en Ginebra, Suiza, en la cual se establecieron las cinco vías de reforma al régimen (UNCTAD, 2015, pág. 6).

En las reuniones mantenidas en Nairobi - Kenia en 2016, se avanzó con la reforma al RAll, instando a alinear los avances con los objetivos de desarrollo sostenible y la agenda 2030, para lo cual se recomienda considerar el Marco de Políticas de Inversión para el Desarrollo Sostenible y la Hoja de Ruta para la Reforma de los All desarrollados en años anteriores. Entre otros de los avances pragmáticos, se propugna la consecución de "un tribunal multilateral de inversiones, un mecanismo de apelación y los principios directivos para la formulación de políticas de inversión" (International Institute for Sustainable Development, 2016).

Para Ginebra - Suiza 2018, se incorporaron las instituciones financieras y las tecnologías de la información a los esfuerzos de la reforma con el fin de poder buscar las mejores prácticas enmarcadas en el alcance de los objetivos de desarrollo sostenible. Para ello, se incluyó una lista de principios para que las inversiones sean sostenibles y para que se garantice el acceso a los flujos de financiamiento considerando además políticas de empoderamiento femenino (UNCTAD, 2018, págs. 3-8).

Este tipo de foros internacionales y reuniones de expertos han servido como espacios de debate y de generación de ideas sin ningún tipo de acción vinculante para los gobiernos participantes, que siguen actuando con autonomía y acogiéndose de forma pragmática a los avances internacionales, recogiendo los aportes para la construcción de la mejor estrategia para atraer flujos de inversión extranjera y financiamiento que para América Latina $-\mathrm{y}$, específicamente, para Ecuador- han sido esquivos, puesto que de la inversión extranjera global que supera los 2 billones de dólares en la actualidad, no llega al país ni el 1\%, como se analiza en las siguientes líneas.

\section{Situación de la inversión extranjera en ecuador entre 2007 y 2019}

Los avances en su regulación han apoyado el aumento de la Inversión Extranjera directa en los últimos 36 años a nivel global, en términos generales. El promedio de salida anual de IED a nivel mundial aumentó de \$27,9 mil millones de dólares en 1975 a \$2,1 billones de dólares en 2018; es decir casi 8 veces más. El año 2007 es el que registra el valor más alto de salidas de IED con $\$ 3,2$ billones de dólares (Banco Mundial, 2019). Mientras que 2010 y 2018, son los años que registraron un menor flujo de salidas en el siglo XXI, con un promedio anual de \$1,3 billones de dólares. En 2018, para los países en desarrollo se han destinado $\$ 671$ mil millones de dólares (51,6\% de los flujos globales de IED en 2018), para América Latina y el Caribe la IED ha ascendido a $\$ 184,3$ mil millones $(14,1 \%$ del total de IED mundial en 2018) en el mismo año, ínfimos valores que, al desagregar por país, son aún más pobres si los comparamos con los totales a nivel mundial (CEPAL, 2015, págs.19-25). Sin embargo, estos datos responden a una disminución en los flujos globales que en 2018, por tercer año consecutivo, han disminuido, esta vez con una baja de 328,9 mil millones de dólares (23\%) 
respecto de 2017, año en el que la IED mundial llego a $\$ 1,43$ billones de dólares (UNCTAD, 2017).

Si se comparan con los flujos mundiales, el total de IED que se generó a nivel mundial en 2018 es el valor que América Latina recibió entre 1990 y 2018 (\$2,1billones), lo que denota un desinterés por transferir flujos de inversión productiva desde los países desarrollados hacia América Latina (CEPAL, 2016, pág. 84). Del total recibido en 28 años, Brasil y México son los principales captadores, con $\$ 923,2$ mil millones, lo que representa el 39,44\%, y $\$ 480,8$ mil millones, con el $21,66 \%$, respectivamente. Argentina se alza con $\$ 179,3$ mil millones; Colombia, con $\$ 140,1$ mil millones y el $6.04 \%$, siendo el mayor receptor de inversión del bloque económico; Perú, con $\$ 114,3$ millones, lo que representa el 5,28\%; Ecuador, con $\$ 17,1$ mil millones de dólares; y Bolivia, con $\$ 14,5$ mil millones de dólares. $\mathrm{El}$ Caribe, por su parte, se alza con $\$ 37,6$ mil millones de dólares (CEPAL,2019, pág. 28). Los países de América Latina especialmente se han vuelto competidores directos por la atracción de IED e intentan capturar la atención de inversores extranjeros por distintas causas, transformando a la región en un mercado cada vez más agresivo (Suanes, 2016, pág. 63).

En América del Sur, la IED ha seguido un patrón de incremento pero nada promisorio para las economías más pequeñas como Ecuador. Según la CEPAL, en 2005 los países de este subcontinente recibían por IED un aproximado de $\$ 68,3$ mil millones de dólares mientras que en 2018 recibían alrededor de $\$ 130$ mil millones de dólares, distribuidos principalmente entre Brasil, Argentina y Colombia, quienes recibieron 88,3, 11,8 y 11,4 mil millones de dólares respectivamente (CEPAL, 2019, pág.28).

Para un país que no cuenta con moneda propia y que no dispone de ahorro interno suficiente para financiar su propio desarrollo, el ingreso de divisas impulsa su crecimiento y se hace esencial. Un mayor flujo de ingresos de IED incrementa la circulación de capitales al interior del país, fortaleciendo el sistema de dolarización y reactivando la economía nacional. En este contexto, para Ecuador, los beneficios que presenta la IED le son indispensables, pero le han sido indiferentes. La implementación de estrategias para atraer mayor IED es la característica fundamental en la mayoría de países del mundo: cada vez mejores oportunidades e incentivos son propuestos, incrementando la competencia por atraer y captar la IED.

Sin embargo, entre 2007 y 2019, el monto de inversión extranjera que ha llegado al Ecuador ha sido de apenas $\$ 9,2$ mil millones de dólares en total. En 13 años, los flujos de IED promedio que han venido al país representan un promedio de $\$ 705$ millones de dólares. En 2018, se registró el año con mayores ingresos por este concepto, llegando la IED a \$1,456 millones de dólares, mientras que en 2008 fue el menor registro con $\$ 161,5$ millones de dólares, lo que denota variaciones considerables de un año frente a otro, provocadas, entre otras cuasas, por la diferencia entre las posturas en los gobiernos frente al regimen de inversiones y a las formas de atraer la inversión, lo que necesariamente invita a preguntarse si Ecuador dispone de una política exterior clara referente al tema, respecto de lo cual se aboradará a continuación (Banco Central del Ecuador, 2019). 


\section{Política exterior ecuatoriana en materia de inversiones entre 2007 y 2019}

En Ecuador, con la llegada de un nuevo gobierno a inicios de 2007, se anunció que no se firmaría Acuerdos de Libre Comercio (TLC) y mucho menos Tratados Bilaterales de Inversión (TBI). Se dispuso la denuncia del CIADI en 2009 por ser un espacio en el que se beneficia a los intereses de las corporaciones de los Países Desarrollados y se confirmó el inicio del proceso de denuncia ante la comunidad internacional de los tratados bilaterales de inversión firmados, en su mayoría, en la década de 1990. Así es como, instalado el nuevo gobierno, se adoptó la determinación de expulsar de Ecuador a Eduardo Somensatto, representante del Banco Mundial en Quito, antecedente a la denuncia y consecuente terminación del convenio con el CIADI, del cual el país formó parte desde 1986, por medio del Decreto Ejecutivo 1823 del 2 julio de 2009. Se procedió, además, a denunciar los 26 Tratados Bilaterales de Inversión vigentes al 2008 y se concretó la idea de no firmar acuerdos comerciales, al menos hasta el 1 de enero de 2017, fecha en la que entró en vigencia el Acuerdo Multipartes entre Ecuador y la Unión Europea.

Ante la corriente global de regulación de la inversión que se creó y se instituyó en el siglo XX, la renovada política ecuatoriana ha adoptado una posición contraria a la del establishment entre 2007 y 2017. Sin embargo, desde el 2018, con la asunción de Lenin Moreno a la Presidencia y Pablo Campana como Ministro de Comercio Exterior, la situación dio un vuelco completo, designándose a la apertura de mercados como la estrategia para atraer flujos de inversión extranjera. Dicha estrategia implicaba dos cuestiones básicas: la implementación de una normativa que reforme y complemente el Libro II del COPCl, así como la necesidad de negociar y firmar una mayor cantidad de Tratados Bilaterales de Inversión. Respecto de la primera iniciativa, se aprobó la Ley de Promoción y Atracción Productiva de la Inversión Extranjera en agosto de 2018, la que viene a constituir un reemplazo a la Ley de Promoción y Garantía de Inversiones del año 1997. Respecto de la segunda, se trabajó en un formato de acuerdo marco para la firma de TBI en la Procuraduría General del Estado.

Ambas decisiones están enmarcadas en una visión neoliberal y aperturista de la década del noventa y dejan sentada la intención del gobierno ecuatoriano de favorecer la inversión y el capital transnacional, muy contraria a las acciones emprendidas por el gobierno anterior, cuyos esfuerzos por la denuncia de los TBI trascendieron a la creación de un grupo de trabajo compuesto por especialistas que se encargaran de auditar los 30 tratados firmados por Ecuador en su historia, de cuales se encontraron 26 vigentes al 2008 (ver tabla 1), ya que tres no fueron ratificados por la contraparte (con Panamá, Costa Rica y Rusia) y uno no fue renovado (con Egipto).

Tabla 1: Tratados Bilaterales de Inversión firmados por Ecuador y vigentes al 2008

\begin{tabular}{|c|c|c|c|}
\hline País & $\begin{array}{c}\text { Año de entrada } \\
\text { en Vigencia }\end{array}$ & País & $\begin{array}{c}\text { Año de entrada } \\
\text { en Vigencia }\end{array}$ \\
\hline Alemania & 1996 & Honduras & 2006 \\
\hline Argentina & 1995 & Italia & 2005 \\
\hline
\end{tabular}




\begin{tabular}{|c|c|c|c|}
\hline Bolivia & 1997 & Nicaragua & 2002 \\
\hline Canadá & 1997 & Países Bajos & 2001 \\
\hline Chile & 1996 & Paraguay & 1995 \\
\hline China & 1997 & Perú & 1999 \\
\hline Cuba & 1998 & Reino Unido & 1995 \\
\hline El Salvador & 1996 & $\begin{array}{c}\text { República } \\
\text { Dominicana }\end{array}$ & 2006 \\
\hline España & 1997 & Rumania & 1997 \\
\hline EE.UU & 1997 & Suecia & 2002 \\
\hline Finlandia & 2001 & Suiza & 1969 \\
\hline Francia & 1996 & Uruguay & 1995 \\
\hline Guatemala & 2005 & Venezuela & 1995 \\
\hline
\end{tabular}

Fuente: SICE, OEA.

Elaboración: Santiago Núñez.

A este grupo de trabajo se lo denominó Comisión para la Auditoría de los Tratados de Protección Recíproca de Inversiones y del Sistema de Arbitraje Internacional en Materia de Inversiones (CAITISA) y estuvo en funciones desde mayo de 2013 hasta mayo de 2017, fecha en la que emitió su informe final respecto a una auditoría integral de los tratados de protección recíproca de inversiones y del sistema de arbitraje en Ecuador. Para mayo de 2017, amparado en el trabajo realizado por la comisión, Ecuador había anunciado la salida de 16 tratados internacionales en materia de inversión, cuyo proceso ya se había iniciado en 2010: Alemania, Argentina, Bolivia, Canadá, Chile, China, España, Estados Unidos, Francia, Italia, Países Bajos, Perú, Reino Unido, Suecia, Suiza y Venezuela (CAITISA, 2017, págs. 2-10).

Sin embargo, Ecuador había iniciado ya en 2008 la denuncia con países con los que no representaban un flujo de capital sustancial: Cuba, El Salvador, Guatemala, Honduras, Nicaragua, Paraguay, República Dominicana, Rumanía y Uruguay. En 2010, en cambio, había continuado con el proceso de denuncia de los TBI con los siguientes países: Alemania, Argentina, Canadá, Chile, China, Estados Unidos, Finlandia, Francia, Países Bajos, Reino Unido, Suecia, Suiza y Venezuela; a los que se les suma la denuncia de los TBI con Bolivia, España, Italia y Perú. Finlandia fue el único país con el que se terminó la relación legal con la finalización del proceso de denuncia del TBI a finales de 2010. En total, se ha llegado a la denuncia de los 26 tratados mostrados en la tabla 1, de los cuales 20 fueron firmados en la década de 1990 (Bas Vilizzio, 2015, págs. 239-240).

En este contexto, el gobierno ecuatoriano ha iniciado un proceso de renegociación de los tratados bilaterales de inversión que ofrezcan seguridad jurídica a las inversiones extranjeras y una vuelta al sistema internacional de solución de controversias. Desde lo discursivo y práctico, las acciones se enmarcan en una estrategia obsoleta y poco innovadora que no responde a la tendencia global actual que implica una menor cantidad de acuerdos firmados, que en el campo de la inversión han demostrado disminuir dramáticamente. Esta estrategia tampoco responde a lo demostrado en el informe de la CAITISA (2017), donde se 
explica, amparados por la CEPAL y UNCTAD, que "los factores de atracción más importantes de IED que determinan al país destino de sus inversiones, varía según el interés primordial del inversionista" (pág. 64); es decir, la ubicación de los flujos de IED no dependen del número de tratados internacionales firmados por el país receptor, tal como se explica a continuación.

Brasil, al 2019, no ha ratificado ningún TBI; sin embargo, recibe importantes cantidades de inversión extranjera, lo que lo convierten en el principal destino de América del Sur para la IED. El país firmó 14 TBI en la década de 1990, pero el Congreso de ese país se negó a ratificarlos a causa de los riesgos potenciales asociados con el sistema de solución de controversias tradicional. A pesar de estas acciones, Brasil ha implementado en su normativa interna algunos elementos clave de los TBI (como la igualdad en el trato a los inversionistas extranjeros).

Sudáfrica, por su parte, ha dado por terminados sus tratados de inversión y ha sustituido su régimen de TBI por una nueva legislación interna que no contempla recurrir al arbitraje internacional sino utilizar los mecanismos locales de solución de controversias, de presentarse alguna. Este hecho ha sido observado y tomado como referente por países en desarrollo, quienes ven en este país emergente un ejemplo de desarrollo económico.

Mientras tanto China, influenciado por sus socios, intenta sobrellevar un enfoque más flexible frente a los All, firmando algunos acuerdos de inversión, sin incluir cláusulas de arbitraje internacional, por ejemplo, en el TBI, convenido con Taiwán en 2012. Fiel a su estrategia de softpower, China maneja de forma pragmática la firma de convenios, siempre y cuando no se contrapongan a los principios de autonomía y soberanía ni contravengan sus intereses económicos.

El caso de Rusia es particular, ya que sus modelos de TBI no contienen disposiciones expansivas que usualmente se encuentran en la mayoría de los acuerdos internacionales de inversión. El enfoque de Rusia permite el trato discriminatorio de los inversionistas extranjeros, excluyéndolos de ciertos sectores de la economía y reservándose el derecho de incluir excepciones en el trato nacional.

Finalmente, India recientemente ha adoptado una posición más cuidadosa, después de que inversionistas extranjeros impusieran demandas sobre varias medidas tomadas por el gobierno local y llevaran las controversias a arbitraje. A partir del 2012, India ha iniciado una revisión a sus tratados de inversión y ha elaborado un nuevo modelo de TBI (Singh, 2014, págs. 1-2).

En la misma línea, Bolivia e Indonesia han expresado su posición de denuncia de los TBI. Ecuador, por su parte, ha denunciado hasta 2017 la poca facultad de la que disponía el Estado para enfrentar arbitrajes que lo perjudicaban, por lo que implementó una política de recuperación de la soberanía desde 2007, en respuesta al embate de controversias de inversiones que ha sufrido el país. Esto lo ha posicionado como el tercero con mayor número de demandas en materia de inversiones a nivel internacional. Hasta 2017, se cuestionaba la legitimidad del SCIE, manifestando la necesidad de impulsar su replanteamiento desde la multilateralidad (Pino, 2014, págs.1-2). 
Esta vía de acción que seguía Ecuador para reformar el Régimen de Acuerdos Internacionales de Inversión (RAll) permitió llegar a un consenso sobre la necesidad de llevar a cabo una reforma, tanto del régimen de All como del sistema de solución de controversias relacionado a este, de forma integral y gradual, tomando en cuenta los intereses de todas las partes involucradas, hechos que estaban de acuerdo con los avances internacionales, tal como se demostró anteriormente respecto de los resultados de los Foros Mundiales de Inversión.

No obstante, desde mediados de 2017 y hasta finales de 2019, estos esfuerzos se han visto menoscabados por una visión aperturista del país que intenta respaldar la atracción de inversión extranjera en una renovada visión aperturista de mercado y de nuevas negociaciones de tratados de protección a la inversión que provenga del exterior.

\section{Conclusiones}

Se ha realizado un análisis profundo respecto de la posición de Ecuador frente al régimen internacional de inversiones en tres dimensiones: histórica, situacional y política, lo que permite concluir de forma general que el Estado ecuatoriano no ha planificado, mucho menos ejecutado, una estrategia consistente entre 2007 y 2019 para la retención y atracción de flujos de inversión extranjera directa.

Los aportes críticos que se han ofrecido a lo largo del documento posibilitan concluir que no ha existido tampoco una política exterior planificada, coherente y vinculada con las demás políticas emprendidas por el gobierno en otros temas (tributarios, legales o laborales), y que las acciones adoptadas por el gobierno mandante en materia de protección y promoción de la inversión en el periodo en mención no han servido para mejorar los flujos de inversión extranjera directa proveniente del exterior ni su calidad.

Se ha demostrado que los flujos de inversión extranjera directa varían en consecuencia con el contexto internacional y con las acciones emprendidas por los gobiernos de turno, que, en el caso ecuatoriano, han sido contrapuestas y pragmáticas a sus intereses. Dichas acciones no han promovido un crecimiento sostenido de la inversión extranjera en Ecuador, las que en años consecutivos han sufrido altas variaciones que responden a una variación de los flujos de más del $100 \%$ de un año con otro, tanto de incremento como de disminución.

Si bien el contexto internacional ha contribuido a una ralentización de flujos de IED hacia países en desarrollo, hacia países en América Latina y el Caribe, hacia países de América del Sur y mucho más hacia las pequeñas economías de la región, como se ha demostrado anteriormente; los gobiernos ecuatorianos entre 2007 y 2019 no han demostrado implementar una relación lógica ni efectiva en su política interna ni externa respecto a la atracción de inversiones. De ahí es que se manifieste, de forma concluyente, que Ecuador haya prescindido de una estrategia de Estado sólida, pensada o elaborada que trascienda a los momentos políticos y que permita el fortalecimiento del atractivo país, la balanza de pagos y la dolarización.

La posición ecuatoriana frente al régimen internacional de inversiones ha sido variable y difusa, la cual no ha recogido resultados positivos en la atracción de flujos de IED, y sus 
argumentos frente a la firma de TBI se han desvanecido por falta de sostenibilidad y competitividad en la gestión gubernamental, ya que se ha demostrado a lo largo del documento que países que disponen de TBI reciben altos flujos de IED, así como otros que no los han firmado, de igual forma. De ahí es que el discurso político actual de Ecuador respecto de que la inversión mejorará con la consecución de más acuerdos no tenga asidero técnico y que la función de dichos instrumentos legales sea principalmente precautelar los intereses de los inversores, tema que se ha puesto en debate en foros internacionales y mesas de diálogo y que ha creado una dicotomía a nivel mundial.

Ecuador, entre 2007 y 2019 no ha sido capaz de competir en el mercado sudamericano de la IED, en parte, por las tendencias globales de ralentización pero también por circunstancias internas relacionadas con una escaza capacidad técnica para la toma de decisiones, por los insuficientes esfuerzos diplomáticos y comerciales en la materia, y por una persistente indisposición política por recoger los aprendizajes respecto al tema; lo que ha provocado un débil crecimiento de los flujos de inversión extranjera directa y un discreto posicionamiento del país como un lugar atractivo para el inversionista extranjero.

\section{Referencias bibliográficas}

Banco Central del Ecuador, (3 de diciembre de 2019). Inversión Extranjera Directa IED, Contenido BCE.

https://contenido.bce.fin.ec/documentos/Administracion/bi_menulED.html.

Banco Mundial, (5 de doiciembre de 2019). Inversón Extanjera Directa, salidas netas. Datos Banco Mundial. https://datos.bancomundial.org/indicator/BM.KLT.DINV.CD.WD.

Bas Vilizzio, M. (2015). Solución de controversias en los tratados bilaterales de inversión: mapa de situación en América del Sur, Revista de la Secretaría del Tribunal Permanente de Revisión. 3(5). 233-253. http://dx.doi.org/10.16890/rstpr.a3.n5.233.

Código Orgánico de la Producción, Comercio e Inversiones [COPCI], (Ley 0, Registro Oficial Suplemento 351 del 29 de diciembre de 2010, modificado en 2018 (Ecuador).

Comisión Económica para América Latina y el Caribe, (2015). La inversión extranjera directa en América Latina y el Caribe. Editorial CEPAL. https://repositorio.cepal.org/bitstream/handle/11362/38214/9/S1500535_es.pdf.

Comisión Económica para América Latina y el Caribe, (2016). La inversión extranjera directa en América Latina y el Caribe. Editorial CEPAL.

https://repositorio.cepal.org/bitstream/handle/11362/40213/7/S1600664_es.pdf.

Comisión Económica para América Latina y el Caribe, (2019).La inversión extranjera directa en América Latina y el Caribe. Editorial CEPAL.

https://repositorio.cepal.org/bitstream/handle/11362/44697/8/S1900448_es.pdf 
Comisión para la Auditoría Integral Ciudadana de los Tratados de Protección Recíproca de Inversiones y del Sistema de Arbitraje Internacional en Materia de Inversiones, (2017). Informe Ejecutivo, Auditoría Integral Ciudadana de los Tratados de Protección Recíproca de Inversiones y del Sistema de Arbitraje en materia de Inversiones en Ecuador. Editorial IAEN. https://drive.google.com/file/d/14m0VnGIHNzuNVRVJRIOFDXqh9agGMC4x/view.

Fondo Monetario Internacional, (2009). Categorías Funcionales, Manual de Balanza de Pagos y Posición de Inversión Internacional (Sexta edición MBP6, FMI, 105-126). file://C:/Users/Santiago/AppData/Local/Temp/bopman6s.pdf

Gitman, L. y Joehnk, M. (2009). Fundamentos de Inversiones, Pearson Educación. Décima edición, 1-650 Naucalpan de Juárez, México.

International Institute for Sustainable Development, (12 de diciembre de 2016). Conferencia sobre los Acuerdos Internacionales de Inversión de la UNCTAD 2016: Llevando la Reforma de Alls al Próximo Nivel, [Resumen de presentación de la conferencia]. Foro mundial de inversiones desarrollado en Nairobi, Kenia. https://www.iisd.org/itn/es/2016/12/12/unctads-international-investmentagreements-conference-2016-taking-iia-reform-to-the-next-level-james-zhandiana-rosert/.

Kato-Vidal, L. (2013). Foreign Investment and Wages: A Crowding out Effect in Mexico. Latin American Journal of Economics, México: Revistas Indizadas. 50(2) 209-231. https://scielo.conicyt.cl/pdf/laje/v50n2/art03.pdf.

Lander, E. (25 de abril de 1998). El Acuerdo Multilateral de Inversiones (MAl): el capital diseña una Constitución Universal, [Archivo PDF]. Transnational Institute. https://www.tni.org/files/El\%20Acuerdo\%20Multutilateral\%20de\%20Inversiones\%20\%28AMI\%29.pdf.

Montoya, C. (2006). La inversión extranjera como determinante del desarrollo en América Latina, Revista Ciencias Estratégicas, 14(15), 21-31. https://www.redalyc.org/pdf/1513/151320329002.pdf.

Organización para la Cooperación y el Desarrollo de Económico, (2011). OCDE Definición Marco de Inversión Extranjera Directa, (Cuarta Edición, Éditions OCDE, 1-290). https://read.oecd-ilibrary.org/finance-and-investment/ocde-definicion-marcode-inversion-extranjera-directa_9789264094475-es\#page1.

Pino, C, (16 de octubre de 2014). Lead Discussants and Statements, UNCTAD, World investment forum. [Resumen de presentación de la conferencia]. Reforming the International Investment Agreements Regime, IIA Conference, GinebraSuiza.

https://worldinvestmentforum.unctad.org/programme2014/sessions/reformi ng-the-international-investment-agreements-regime/.

Prieto, G, (2012). Evolución del Derecho Internacional de inversiones: hacia un régimen globla estable, Foro, Revista de Derecho. 17 (1), 1-26.

https://revistas.uasb.edu.ec/index.php/foro/article/view/405/400. 
Suanes, M, (2016). Inversión extranjera directa y desigualdad de los ingresos en América Latina. Un análisis sectorial, Revista Cepal, 118 (1), 49-66.

https://repositorio.cepal.org/bitstream/handle/11362/40027/1/RVE118_Suan es.pdf.

Singh, K, (25 de febrero de 2015). Transformation of the International Investment Agreement Regime: A BRICS perspective. UNCTAD - World Investment Forum. Recuperado el 27 de julio de 2019 de https://www.madhyam.org.in/transformation-ofthe-international-investment-agreement-regime-a-brics-perspective/.

UNCTAD, (1 de octubre de 2008a). Regulación internacional de la inversión: balance, retos y camino a seguir, [Archivo PDF]. UNCTAD. http://unctad.org/es/Docs/iteiit20073_sp.pdf.

(25 de abril de 2008b). La Declaración de Accra y el Acuerdo de Accra. [Archivo PDF]. UNCTAD. http://unctad.org/es/Docs/tdl413_sp.pdf.

(21-26 de abril 2012). Cumbre de líderes mundiales sobre la inversión. [Archivo PDF]. http://unctad.org/meetings/es/SessionalDocuments/td469_sp.pdf.

(19 de julio de 2013). Towards a new generation of internacional investment policies: UNCTAD'S fresh approach to multilateral investment policy-making. [Archivo PDF]. https://unctad.org/en/PublicationsLibrary/webdiaepcb2013d6_en.pdf .

(25-27 de febrero de 2015). Transformación del Régimen de acuerdos internacionales de inversión. [Archivo PDF].

http://unctad.org/meetings/es/SessionalDocuments/ciiem4d2_es.pdf.

(1 de junio de 2017). Informe sobre las inversiones en el mundo. [Archivo PDF]. https://unctad.org/es/PublicationsLibrary/wir2017_overview_es.pdf.

(1 de junio de 2018). World Investment Report. [Archivo PDF]. https://unctad.org/en/PublicationsLibrary/wir2018_en.pdf. 


\section{afers internacionals}

\author{
SANCIONES \\ INTERNACIONALES \\ SUSOTROSEFECTOS \\ Clara Portela \\ y Martijn C. Vlaskamp (coords.)
}

\section{5}

Septiembre

2020

Si bien la investigación académica ha analizado extensamente las sanciones desde el punto de vista de sus emisores, menos atención han recibido otro tipo de impactos, tales como los efectos sobre los destinatarios, la política doméstica de los propios emisores o sobre terceros estados. Este número de Revista CIDOB d'Afers Internacionals se interroga sobre esos otros efectos. Un primer bloque examina las reacciones de los destinatarios, revisa la evaluación académica de la eficacia de las sanciones y se interesa por la regulación de los «minerales de conflicto» como nueva forma de sanción. Un segundo bloque se ocupa de los efectos de las sanciones sobre terceros en referencia a los triángulos que forman la UE y Estados Unidos con Cuba, por un lado, y con Rusia y Belarús por otro, así como al posicionamiento asiático respecto a las sanciones occidentales contra Rusia. Por último, se analiza el impacto de las sanciones de la UE contra Irán y Rusia sobre alguno de sus estados miembros.
Clara Portela

y Martijn C. Vlaskamp

Alexandra Hofer

Lee Jones

y Clara Portela

Ilari Aula

Arturo López-Levy

Ryhor Nizhnikau

Maria Shagina

Paloma González del Miño

y David Hernández

Martínez

Ruth Ferrero-Turrión
EDITA

CIDOB

Elisabets, 12, 08001

Barcelona

www.cidob.org

\section{DISTRIBUYE}

Edicions Bellaterra, S.L.

Navas de Tolosa, 289 bis, 08026 Barcelona unw.ed-bellaterra.com 